\title{
AVALIAÇÃO FÍSICO-QUÍMICA DE CAFÉS TORRADOS E MOÍDOS, DE DIFERENTES MARCAS COMERCIAIS, DA REGIÃO SUL DE MINAS GERAIS
}

\author{
Renata LICCIARDI', Rosemary Gualberto F. A. PEREIRA', \\ Luciana Maria Vieira Lopes MENDONÇA", Elisângela Ferreira FURTADO
}

\begin{abstract}
RESUMO
A manutenção das características sensoriais de uma determinada marca de café torrado e moído, a cada produção de um novo lote, tem sido uma das maiores dificuldades enfrentadas pelas torrefadoras, devido à heterogeneidade da matéria-prima utilizada na elaboração dos blends. A composição química do café cru é responsável pelos atributos sensoriais da bebida, que são formados durante o processo de torração e variações nestes componentes acarretam bebidas diferenciadas. Com base neste fato, amostras de onze marcas comerciais de café torrado e moído, comercializadas na região Sul de Minas Gerais, foram coletadas nos meses de janeiro, abril e julho, e avaliadas quanto aos teores de extrato aquoso, extrato etéreo e cafeína. Os resultados demonstraram existir diferenças entre as marcas avaliadas e as épocas de coleta; cuja interação foi significativa para todas as variáveis analisadas. Apenas o teor de cafeína não apresentou diferença entre as marcas, durante o mês de janeiro. Os resultados obtidos para extrato aquoso, extrato etéreo e cafeina encontram-se dentro dos limites estipulados pela legislação vigente. Foram observadas diferenças nos valores das variáveis estudadas para uma mesma marca, em função da época de coleta, demonstrando a necessidade de maior padronização da matéria-prima utilizada e do processo de elaboração de blends para a fabricação do café torrado e moído.

Palavras-chave: café torrado; cafeína; extrato aquoso; extrato etéreo; qualidade.
\end{abstract}

\section{SUMMARY}

LEVELS OF AQUEOUS EXTRACT, ETHEREAL EXTRACT AND CAFFEINE IN ROASTED AND GROUND COFFEES OF DIFFERENT BRANDS, FROM THE SOUTH OF MINAS GERAIS. The maintenance of the sensorial characteristics of a certain brand of roasted and ground coffee, to each production of a new lot, has been one of the largest difficulties faced by the roasted processors, due to the heterogeneity of the raw material used in the elaboration of the blends. The chemical composition of the raw coffee is responsible for the sensorial attributes of the drink. The flavour is formed during the roasted process and variations in these components cart differentiated drink. Based on to this fact, samples of eleven trademarks of toasted and ground coffee, marketed in the South of Minas Gerais, were collected in the months of January, April and July, and analyzed for the levels of aqueous extract, ethereal extract and caffeine. The results demonstrated differences among the appraised marks and among the collection times; the interaction between both being significant for all the analyzed variables. Only the caffeine content didn't present a difference between the makes, during the month of January. The results obtained for aqueous extract, ether extract and caffeine were within the limits of current law. Differences were observed in the values of the variables studied for a single make in the collection time, demonstrating the need for larger standardization of the raw material used and for the process of blends for the production of the toasted and ground coffee.

Keywords: roasted coffee; caffeine; aqueous extract; ethere extract; quality.

\section{1 - INTRODUÇÃO}

Os atributos sensoriais da bebida do café estão intimamente relacionados com a composição química do grão de café cru, que atua como precursora dos componentes do aroma e sabor [5].

No Brasil, a Associação Brasileira das Indústrias do Café (ABIC), criou o selo de pureza em 1989, visando proporcionar ao consumidor a segurança em adquirir um café livre de impurezas, sem adulteração ou fraudes [1]. Este selo da ABIC, contudo, não garante a qualidade dos aspectos sensoriais da bebida.

A composição química do grão de café cru depende de fatores genéticos, ambientais e condições de manejo

Recebido para publicação em 02/12/2002. Aceito para publicação em 25/07/2005(001016)

Departamento de Ciência dos Alimentos, Universidade Federal de Lavras. CEP: 37200-000, Lavras, MG, Brasil. E-mail: rosegfap@ufla.br/lisffurtado@bol.com.br

Laboratório de Bromatologia e Água, Escola Agrotécnica Federal de Muzambinho. Caixa Postal: 02. CEP: 37890-000, Muzambinho-MG. E-mail: luciana@eafmuz.gov.br

A quem a correspondência deve ser enviada. pré e pós-colheita [6] e, segundo os autores, a torração é uma etapa essencial para a produção de compostos que conferem as características de aroma e sabor do café. Os açúcares e as proteínas do grão cru são os principais compostos que contribuem para o sabor e aroma do café torrado.

O teor de extrato aquoso pode servir como um indício da ocorrência de fraude ou adulteração no café torrado, devendo ser, no mínimo, de $20 \%$, conforme a legislação vigente [3].

Os resultados da avaliação do extrato aquoso em café, e em misturas de café com milho e com cevada, demonstraram um aumento na concentração desta variável nas amostras de cafés adulterados [10]. O café sem mistura apresentou 30\% de extrato aquoso, e nas amostras em que foram adicionados $10 \%$ de milho e $10 \%$ de cevada, os valores encontrados foram de $34,1 \%$ e $33,8 \%$, respectivamente, contradizendo a legislação.

Diversas substâncias estão relacionadas ao extrato aquoso. Em análises realizadas por cromatografia líquida de alta eficiência (CLAE), alguns componentes do extrato aquoso foram identificados como cafeína, trigonelina e ácido-5-cafeoilquínico [7]. 
Os triglicerídeos do grão do café são pouco afetados pela torração, sofrendo apenas pequena hidrólise e decomposição, com liberação de ácidos graxos e formação de produtos voláteis. Muitos lipídios são retidos nas estruturas celulares do grão, onde o dióxido de carbono formado a partir da decomposição de carboidratos, os protege contra oxidações. Nas torrações mais escuras, muitas células sofrem rompimento e o óleo pode migrar para a superficie do grão, ficando susceptivel às oxidações atmosféricas [8]. O Ministério da Saúde estipula o teor mínimo de $8 \%$ extrato etéreo para o café torrado e moído [3].

Os grãos de café foram as primeiras fontes para extração industrial de cafeína, cujos teores variam de acordo com a espécie. O grão cru de café arábica contém, em média, $1,2 \%$ do alcalóide, enquanto que o robusta apresenta um teor médio de 2,0\% [5]. A cafeína é bastante estável, não sofrendo grandes alterações durante a torração. A Portaria no 377, de 26 de abril de 1999, fixa o teor mínimo de $0,7 \%$ de cafeína no café torrado e moído [3].

As indústrias de torrefação encontram dificuldades na preservação das caracteristicas relacionadas ao padrão de qualidade do café torrado e moído adotado pela empresa devido, principalmente, à disponibilidade e heterogeneidade do café cru. Conseqüentemente, devido a esta variabilidade do café comercializado, o consumidor muitas vezes adquire marcas distintas durante o ano, em busca daquela que satisfaça suas exigências [10].

Numa reação a todos estes problemas enfrentados, mudanças significativas têm ocorrido na comercialização e no consumo do café torrado e moído. Os consumidores estão conscientes sobre a importância da segurança higiênico-sanitária do produto, e de maiores conhecimentos sobre os atributos qualitativos da bebida [5]. O setor industrial vê-se, assim, obrigado a acompanhar a evolução deste mercado, oferecendo produtos diferenciados e criando estratégias para a valorização das marcas que preservem os aspectos desejados pelo consumidor, como o selo de pureza criado pela ABIC [1].

Com tudo isso, foi objetivo do presente trabalho determinar o percentual de extrato aquoso, extrato etéreo e cafeína de onze marcas de cafés torrados e moídos, comercializadas na região sul de Minas Gerais, em diferentes épocas do ano.

\section{2 - MATERIAL E MÉTODOS}

\section{1 - Caracterização do experimento}

Foram avaliadas onze marcas diferentes de café torrado e moído, comercializadas em embalagem do tipo almofada, na região Sul de Minas Gerais. As amostras foram adquiridas nos municipios de Lavras, Varginha e Três Pontas nos meses de janeiro, abril e julho do ano de 2000, em estabelecimentos comerciais, e identificadas por códigos. As datas de fabricação, o prazo de validade e a presença do selo de pureza da ABIC foram registrados (Tabela 1).
TABELA 1 - Dados das amostras coletadas, data de coleta e fabricação, prazo de validade, municipio de coleta e presença de sele de pureza ABIC

\begin{tabular}{|c|c|c|c|c|c|}
\hline $\begin{array}{c}\text { Café } \\
\text { (Marca) }\end{array}$ & $\begin{array}{c}\text { Data de } \\
\text { Coleta } \\
\text { (ano 2000) }\end{array}$ & $\begin{array}{c}\text { Data de } \\
\text { Fabricação }\end{array}$ & $\begin{array}{c}\text { Prazo de } \\
\text { Validade } \\
\text { (dias) }\end{array}$ & Município & $\begin{array}{l}\text { Selo de } \\
\text { Pureza } \\
\text { ABIC }\end{array}$ \\
\hline A & $\begin{array}{c}10 \text { janeiro } \\
15 \text { abril } \\
28 \text { julho }\end{array}$ & $\begin{array}{l}07 / 01 / 2000 \\
07 / 04 / 2000 \\
03 / 07 / 2000\end{array}$ & 90 & Lavras & Não \\
\hline B & $\begin{array}{l}10 \text { janeiro } \\
15 \text { abril } \\
28 \text { julho }\end{array}$ & $\begin{array}{l}04 / 01 / 2000 \\
12 / 04 / 2000 \\
04 / 07 / 2000\end{array}$ & 90 & Lavras & Sim \\
\hline c & $\begin{array}{l}10 \text { janeiro } \\
15 \text { abril } \\
28 \text { julho }\end{array}$ & $\begin{array}{l}07 / 01 / 2000 \\
07 / 04 / 2000 \\
03 / 07 / 2000\end{array}$ & 90 & Lavras & Sim \\
\hline D & $\begin{array}{l}12 \text { janeiro } \\
15 \text { abril } \\
28 \text { julho }\end{array}$ & $\begin{array}{l}07 / 01 / 2000 \\
27 / 03 / 2000 \\
14 / 07 / 2000\end{array}$ & 90 & Três Pontas & Sim \\
\hline E & $\begin{array}{l}12 \text { janeiro } \\
15 \text { abril } \\
28 \text { julho }\end{array}$ & $\begin{array}{l}03 / 12 / 1999 \\
07 / 04 / 2000 \\
17 / 07 / 2000\end{array}$ & 90 & Três Pontas & Sim \\
\hline F & $\begin{array}{l}12 \text { janeiro } \\
15 \text { abril } \\
28 \text { julho }\end{array}$ & $\begin{array}{l}20 / 12 / 1999 \\
04 / 04 / 2000 \\
25 / 07 / 2000\end{array}$ & 90 & Três Pontas & Sim \\
\hline G & $\begin{array}{l}12 \text { janeiro } \\
15 \text { abril } \\
28 \text { julho }\end{array}$ & $\begin{array}{l}08 / 01 / 2000 \\
05 / 04 / 2000 \\
25 / 07 / 2000\end{array}$ & 90 & Três Pontas & Não \\
\hline H & $\begin{array}{l}12 \text { janeiro } \\
15 \text { abril } \\
28 \text { julho }\end{array}$ & $\begin{array}{l}07 / 01 / 2000 \\
17 / 03 / 2000 \\
09 / 05 / 2000\end{array}$ & 180 & Varginha & Sim \\
\hline I & $\begin{array}{l}12 \text { janeiro } \\
15 \text { abril } \\
28 \text { julho }\end{array}$ & $\begin{array}{l}15 / 12 / 1999 \\
25 / 03 / 2000 \\
25 / 06 / 2000\end{array}$ & 60 & Varginha & Sim \\
\hline $\mathrm{J}$ & $\begin{array}{l}10 \text { janeiro } \\
15 \text { abril } \\
28 \text { julho }\end{array}$ & $\begin{array}{l}07 / 01 / 2000 \\
11 / 04 / 2000 \\
30 / 06 / 2000\end{array}$ & 180 & Varginha & Sim \\
\hline L & $\begin{array}{l}10 \text { janeiro } \\
15 \text { abril } \\
28 \text { julho }\end{array}$ & $\begin{array}{l}04 / 01 / 2000 \\
11 / 04 / 2000 \\
23 / 07 / 2000\end{array}$ & 90 & Varginha & Sim \\
\hline
\end{tabular}

Foram coletadas 6 embalagens de $250 \mathrm{~g}$ de café torrado e moído, totalizando $1,5 \mathrm{~kg}$ de amostra, por repetição, para cada marca avaliada.

As análises físico-químicas e químicas foram realizadas nos laboratórios de Grãos e Cereais do Departamento de Ciência dos Alimentos/UFLA, e no Laboratório de Qualidade de Café "Dr. Alcides Carvalho" localizado na Fazenda Experimental da EPAMIG, Centro Tecnológico do Sul de Minas, em Lavras/MG.

\section{2 - Metodologia analitica}

\subsection{1 - Cafeina}

A extração foi realizada em 2 gramas da amostra em béquer, no qual adicionou-se $4 \mathrm{~mL}$ de ácido sulfúrico. A mistura foi homogeneizada e aquecida em banho-maria a $60^{\circ} \mathrm{C}$ por 15 minutos, sendo então filtrada. Lavou-se o béquer e o funil com $30 \mathrm{~mL}$ de água acidulada (para cada $10 \mathrm{~mL}$ de água adiciona-se 1 gota de $\mathrm{H}_{2} \mathrm{SO}_{4}$ ). O filtrado foi colocado em funil de separação (decantação) de $250 \mathrm{~mL}$, no qual adicionou-se $30 \mathrm{~mL}$ de clorofórmio, procedendose a agitação. Realizou-se a separação, filtrando a mistura de clorofórmio que se encontrava na camada inferior, tomando o cuidado de não deixar passar junto o resíduo da cafeína. Essa etapa foi realizada três vezes. Evaporouse a mistura que continha a cafeína em rota vapor até a secagem quase completa, sendo finalizada em estufa. Lavou-se os balões com água destilada quente, colocando esta água em balão de $1.000 \mathrm{~mL}$, para o qual completou-se o volume. A leitura em espectrofotômetro foi realizada a $274 \mathrm{nM}$. Usou-se o método colorimétrico descrito 
pelo IAL [9].

\subsection{2 - Extrato aquoso}

Pesou-se $1 \mathrm{~g}$ de amostra e, posteriormente, adicionaram-se $100 \mathrm{~mL}$ de água quente. As amostras foram submetidas a aquecimento por 1 hora. A solução foi transferida para um balão volumétrico de $250 \mathrm{~mL}$. Esse balão foi resfriado e completou-se o volume. Em seguida, o material foi filtrado e retiraram-se $25 \mathrm{~mL}$ do filtrado para um béquer de $50 \mathrm{~mL}$, previamente aquecido em estufa a $105^{\circ} \mathrm{C}$, por 1 hora, resfriado em dessecador com cloreto de cálcio e pesado. Posteriormente, a solução foi concentrada em banho-maria. Após a secagem, o béquer com o material foi aquecido em estufa a $105^{\circ} \mathrm{C}$ até peso constante [9].

\subsection{3 - Extrato etéreo}

A extração foi realizada em 2 gramas da amostra acondicionada em reboiler da Tecnal, durante 6 horas, usando como extrator o éter etílico em aparelho do tipo Soxhlet [2]. O solvente foi recuperado por destilação e o reboiler que continha o extrato etéreo foi levado à estufa $\left(105^{\circ} \mathrm{C}\right)$ por 2 horas e pesado.

\section{3 - Delineamento experimental e análise esta- tística}

O delineamento experimental utilizado foi o inteiramente casualizado em esquema fatorial $3 \times 11$ (Épocas $\mathrm{x}$ Marcas), com 3 repetições. Os dados foram avaliados através do Software SISVAR, sendo os resultados submetidos ao teste de Scott Knott a 5\% de probabilidade.

\section{3 - RESULTADOS E DISCUSSÃO}

Os resultados obtidos permitiram observar diferenças significativas para todas as variáveis analisadas, nas amostras das diferentes marcas comerciais de café torrado e moído, com interação entre as marcas e as épocas de coleta das amostras.

\section{1 - Extrato Aquoso}

Os resultados obtidos para a variável extrato aquoso encontram-se na Tabela 2.

Os resultados do desdobramento da interação época de coleta dentro das marcas demonstraram existir variações significativas. Com exceção da marca J, todas as demais apresentaram maiores valores para o extrato aquoso no mês de julho, que correspondeu à terceira época de coleta.

Com relação aos resultados da análise do desdobramento das marcas para cada época de coleta, observouse uma variação entre as marcas, não existindo uma padronização nos valores para o extrato aquoso.

Segundo PEDRO et al. [11], é comum observar variações nos teores de extrato aquoso, como as verificadas neste trabalho, isso porque o café torrado e moído comercializado geralmente é constituído de misturas de dife-
TABELA 2 - Valores médios de extrato aquoso de onze marcas comerciais de café torrado e moído, coletadas nos meses de janeiro, abril e julho de 2000

\begin{tabular}{cccc}
\hline \multirow{2}{*}{$\begin{array}{c}\text { Café } \\
\text { Marca) }\end{array}$} & \multicolumn{3}{c}{ Extrato aquoso (\%) } \\
\cline { 2 - 4 } & \multicolumn{3}{c}{ Época de coleta (ano 2000) } \\
\cline { 2 - 4 } & Janeiro & Abril & Julho \\
\hline A & $24,56 \mathrm{C} \mathrm{e}, 59 \mathrm{~B} \mathrm{~h}$ & $27,66 \mathrm{~A} \mathrm{~h}$ \\
B & $27,82 \mathrm{~B} \mathrm{c}$ & $25,13 \mathrm{C} \mathrm{h}$ & $31,53 \mathrm{~A} \mathrm{f}$ \\
C & $29,17 \mathrm{C} \mathrm{b}$ & $30,08 \mathrm{~B} \mathrm{~d}$ & $32,51 \mathrm{~A} \mathrm{e}$ \\
D & $27,02 \mathrm{C} \mathrm{d}$ & $27,67 \mathrm{~B} \mathrm{f}$ & $30,96 \mathrm{~A} \mathrm{f}$ \\
E & $28,18 \mathrm{C} \mathrm{c}$ & $31,03 \mathrm{~B} \mathrm{c}$ & $33,85 \mathrm{~A} \mathrm{~d}$ \\
F & $28,75 \mathrm{~B} \mathrm{~b}$ & $28,67 \mathrm{~B} \mathrm{~d}$ & $29,65 \mathrm{~A} \mathrm{~g}$ \\
G & $27,50 \mathrm{C} \mathrm{c}$ & $31,52 \mathrm{~B} \mathrm{c}$ & $37,88 \mathrm{~A} \mathrm{a}$ \\
H & $29,73 \mathrm{~B} \mathrm{a}$ & $26,63 \mathrm{C} \mathrm{g}$ & $35,02 \mathrm{~A} \mathrm{c}$ \\
I & $24,55 \mathrm{~B} \mathrm{e}$ & $33,86 \mathrm{~A} \mathrm{~b}$ & $33,33 \mathrm{~A} \mathrm{~d}$ \\
J & $26,55 \mathrm{~B} \mathrm{~d}$ & $35,45 \mathrm{~A} \mathrm{a}$ & $24,57 \mathrm{C} \mathrm{i}$ \\
L & $24,38 \mathrm{~B}$ e & $35,83 \mathrm{~A} \mathrm{a}$ \\
\hline CV (\%) & \multicolumn{3}{c}{1,22} \\
\hline *Médias seguidas pela mesma letra maiúscula nas linhas (épocas) e minúsculas nas
\end{tabular}

rentes variedades e possui diferentes graus de torração e moagem. Os valores encontrados neste trabalho estão de acordo com os obtidos pelo mesmo autor, que obteve valores entre $25,00 \%$ e $38,98 \%$ e estão dentro das normas em vigor que estipulam, um teor minimo, de $20 \%$ de extrato aquoso para o café torrado e moído comercializado no país [3].

\section{2 - Extrato etéreo}

Os resultados apresentados na Tabela 3 demonstram haver diferenças significativas para a interação entre as 3 épocas de coleta e as 11 marcas de café torrado e moído avaliados, para o teor de extrato etéreo.

Com as análises do desdobramento das épocas de coleta, em relação às marcas avaliadas, verificaram-se variações para os teores de extrato etéreo, exceto para as marcas $\mathrm{F}, \mathrm{H}$ e $\mathrm{J}$, que mantiveram estatisticamente os mesmos valores nas três épocas. As demais marcas, a cada época de coleta, apresentaram valores diferentes para estes constituintes.

TABELA 3 - Valores médios de extrato etéreo de onze marcas comerciais de café torrado e moído, coletadas nos meses de janeiro, abril e julho de 2000

\begin{tabular}{cccc}
\hline \multirow{2}{*}{$\begin{array}{c}\text { Café } \\
\text { (Marca) }\end{array}$} & \multicolumn{3}{c}{ Extrato etéreo (\%) } \\
\cline { 2 - 4 } & \multicolumn{3}{c}{ Época de coleta (ano 2000) } \\
\cline { 2 - 4 } & Janeiro & Abril & Julho \\
\hline A & $16,45 \mathrm{~A} \mathrm{e}$ & $16,01 \mathrm{~B} \mathrm{~d}$ & $16,37 \mathrm{~A} \mathrm{c}$ \\
$\mathrm{B}$ & $17,85 \mathrm{~A} \mathrm{~b}$ & $15,51 \mathrm{~B} \mathrm{e}$ & $14,80 \mathrm{C} \mathrm{f}$ \\
$\mathrm{C}$ & $13,60 \mathrm{~B} \mathrm{i}$ & $12,46 \mathrm{C} \mathrm{h}$ & $14,75 \mathrm{~A} \mathrm{f}$ \\
$\mathrm{D}$ & $12,30 \mathrm{~B} \mathrm{j}$ & $12,31 \mathrm{~B} \mathrm{~h}$ & $13,06 \mathrm{~A} \mathrm{~g}$ \\
$\mathrm{E}$ & $16,36 \mathrm{~A} \mathrm{e}$ & $14,60 \mathrm{C} \mathrm{g}$ & $14,99 \mathrm{~B} \mathrm{e}$ \\
$\mathrm{F}$ & $14,80 \mathrm{~A} \mathrm{~h}$ & $14,87 \mathrm{~A} \mathrm{f}$ & $14,64 \mathrm{~A} \mathrm{f}$ \\
$\mathrm{G}$ & $18,80 \mathrm{~A} \mathrm{a}$ & $18,87 \mathrm{~A} \mathrm{a}$ & $18,48 \mathrm{~B} \mathrm{a}$ \\
$\mathrm{H}$ & $16,01 \mathrm{~A} \mathrm{f}$ & $15,97 \mathrm{~A} \mathrm{~d}$ & $15,76 \mathrm{~A} \mathrm{~d}$ \\
$\mathrm{I}$ & $16,85 \mathrm{~A} \mathrm{~d}$ & $16,32 \mathrm{~B} \mathrm{c}$ & $16,34 \mathrm{~B} \mathrm{c}$ \\
$\mathrm{J}$ & $17,25 \mathrm{~A} \mathrm{c}$ & $17,25 \mathrm{~A} \mathrm{~b}$ & $17,14 \mathrm{~A} \mathrm{~b}$ \\
L & $15,07 \mathrm{C} \mathrm{g}$ & $15,32 \mathrm{~B} \mathrm{e}$ & $15,60 \mathrm{~A} \mathrm{~d}$ \\
\hline CV (\%) & \multicolumn{1}{c}{0,93} \\
\hline Médias seguidas pela mesma letra maiúscula nas linhas (épocas) e minúsculas nas \\
colunas (marcas) năo diferem entre si pelo teste de Scott-Knott a 5\% de probabilidade.
\end{tabular}


Nas análises de desdobramento das marcas dentro de cada época, observa-se que para a primeira coleta, realizada em janeiro, os valores se situaram entre $12,30 \%$ na amostra D e $18,80 \%$ para a amostra G. Teores estatisticamente iguais só foram encontrados nas amostras A e E. Para as épocas de coleta seguintes, ocorreu meno r variação entre as marcas, sendo possivel observar valores iguais para mais de uma amostra.

Os valores obtidos neste trabalho são superiores aos indicados pela legislação vigente que determina um teor mínimo de $8 \%$ extrato etéreo para café torrado e moído [3].

As diferenças encontradas para a variável extrato etéreo podem ser explicadas pelas diferentes misturas de matérias-primas adotadas pelas empresas e pela dificuldade em manter as mesmas condições no processamento do café.

\section{4 - Cafeina}

Os resultados apresentados na Tabela 4 demonstram as diferenças existentes para a interação entre épocas de coleta e marcas comerciais para o teor de cafeína.

TABELA 4 - Valores médios de cafeína de onze marcas comerciais de café torrado e moído, coletadas nos meses de janeiro, abril e julho de 2000

\begin{tabular}{|c|c|c|c|}
\hline \multirow{3}{*}{$\begin{array}{c}\text { Cafë } \\
\text { (Marca) }\end{array}$} & \multicolumn{3}{|c|}{ Cafeina (\%) } \\
\hline & \multicolumn{3}{|c|}{ Época de coleta (ano 2000) } \\
\hline & Janeiro & Abril & Julho \\
\hline $\bar{A}$ & $0,85 \mathrm{~B} \mathrm{a}$ & $0,88 \mathrm{~B} \mathrm{c}$ & $1,06 \mathrm{~A} \mathrm{~b}$ \\
\hline B & $0,84 \mathrm{~B}$ a & $0,79 \mathrm{~B} \mathrm{~d}$ & $1,09 \mathrm{~A} \mathrm{~b}$ \\
\hline $\mathrm{C}$ & $0,85 \mathrm{~B}$ a & $0,79 \mathrm{~B} \mathrm{~d}$ & $1,09 \mathrm{~A} \mathrm{~b}$ \\
\hline D & $0,88 \mathrm{~B}$ a & $1,15 \mathrm{~A}$ a & $1,13 \mathrm{~A}$ a \\
\hline $\mathrm{E}$ & $0,88 \mathrm{~B}$ a & $1,09 \mathrm{~A} \mathrm{~b}$ & $1,14 \mathrm{~A}$ a \\
\hline $\mathrm{F}$ & $0,88 \mathrm{~B}$ a & $1,03 \mathrm{~A} \mathrm{~b}$ & $1,06 \mathrm{~A} \mathrm{~b}$ \\
\hline G & $0,88 \mathrm{~B}$ a & $1,13 \mathrm{~A}$ a & $1,06 \mathrm{~A} \mathrm{~b}$ \\
\hline $\mathrm{H}$ & $0,95 \mathrm{C}$ a & $1,06 \mathrm{~B} \mathrm{~b}$ & $1,15 \mathrm{~A}$ a \\
\hline I & $0,92 \mathrm{~B}$ a & $1,15 \mathrm{~A}$ a & $1,13 \mathrm{~A}$ a \\
\hline $\mathrm{J}$ & $0,91 \mathrm{~B}$ a & $1,12 \mathrm{~A}$ a & $1,15 \mathrm{~A}$ a \\
\hline L & 0,95 B a & $1,23 \mathrm{~A}$ a & $1,18 \mathrm{~A}$ a \\
\hline $\mathrm{CV}(\%)$ & \multicolumn{3}{|c|}{5,57} \\
\hline
\end{tabular}

A análise do desdobramento das épocas de coleta dentro das marcas, apresentou variações significativas. Apenas a marca H não demonstrou uma manutenção no teor de cafeina de suas amostras por pelo menos duas épocas de amostragem. No mês de julho, que corresponde à terceira amostragem, observaram-se os maiores teores de cafeína, para todas as marcas.

A cafeína é um alcalóide que sofre poucas variações em função do processo de torração. Devido a isso, torrações mais severas podem ser monitoradas observandose o teor de cafeina que tende a ser um dos últimos a sofrerem degradações [12].

No desdobramento das marcas dentro das épocas de coleta, pode-se observar um comportamento estável para o teor de cafeina entre as marcas na primeira coleta, embora seja importante considerar que existem diferenças entre os blends utilizados pelas empresas. Na amostragem realizada no mês de abril, correspondente à segunda coleta, houve uma variação no teor de cafeína tendo sido observadas quatro faixas distintas de valores estatisticamente semelhantes. Correspondem a primeira faixa, com os maiores valores, as amostras D, G, I, J e L e as amostras $\mathrm{B}$ e $\mathrm{C}$ que apresentaram os menores teores. A terceira amostragem, no mês de julho, destacou dois grupos, em relação aos valores para a cafeína. Os maiores valores foram apresentados pelas amostras $\mathrm{D}, \mathrm{E}, \mathrm{H}, \mathrm{I}$, $\mathrm{J}$ e L e os menores pelas marcas A, B, C, Fe G.

Os resultados obtidos neste trabalho aproximam-se daqueles encontrados por PEDRO et al. [11], em cafés torrados e moídos comercializados em Campinas, estado de São Paulo, que variaram entre 0,94\% e 1,91\%.

Os dados obtidos estão de acordo com os valores estipulados pela legislação vigente que determina no mínimo $0,7 \%$ de cafeína no café torrado e moído [3].

Variações nos teores de cafeina entre espécies foram registrados por vários autores. CARVALHO, SONDAHL \& SLOMAN [4] observaram teores médios de 1,2\% de cafeína para grãos torrados da espécie Coffea arabica L. e $2 \%$ para o Coffea canephora Pierre.

Vários fatores podem estar relacionados com as alterações observadas nestas amostras, durante as três épocas de colheita. A heterogeneidade da matéria-prima fornecida as torrefadoras, com variação na composição química dos grãos; o indevido armazenamento do grão cru que propicia reações de deterioração dos componentes químicos e/ou ainda a demora excessiva do processo de embalagem, promovendo um contato do café com o ar atmosférico com conseqüente desencadeamento de reações bioquímicas. A falta de padronização na torração dos cafés e na elaboração dos blends é uma das principais causas da variação na qualidade sensorial do café torrado e moído comercializado.

\section{4 - CONCLUSÕES}

As distintas marcas de café comercializadas na região Sul de Minas Gerais, avaliadas no presente trabalho, apresentaram diferenças para os teores de extrato aquoso, extrato etéreo e cafeína e variações destes constituintes químicos durante épocas diferentes de produção do café torrado e moído. Estes resultados demonstram a grande variabilidade dos cafés da região Sul de Minas, já que estes compostos influenciam diretamente a qualidade da bebida.

\section{5 - REFERÊNCIAS BIBLIOGRÁFICAS}

[1] ASSOCIAÇÃO BRASILEIRA DA INDÚSTRIA DE CAFÉ. Anos 80 - Liberdade de preços e combate à fraude. Jornal do Café, ABIC: Rio de Janeiro, v.12, n.138, p. 8 - 9, mai. 2003.

[2] ASSOCIATION OF OFFICIAL ANALYTICAL CHEMISTS. Official Methods of Analysis of the Association of Official Analytical Chemists. Virginia, 1990.1094 p. 
[3] BRASIL. Portaria $\mathrm{n}^{\mathrm{o}}$ 377, de 26 de abril de 1999. Estabelece normas para fixar a identidade $\mathrm{e}$ as características mínimas de qualidade do café torrado em grão e café torrado e moído. Diário Oficial [Republica Federativa do Brasil], Brasilia. 29 abr. 1999, seção 1, n 80-E.

[4] CARVAlHO, A.; SONDAHL, M.R.; SLOMAN, C. Teor de cafeína em seleções de café. In: CONGRESSO BRASILEIRO DE PESQUISAS CAFEEIRAS, 10, Poços de Caldas, 1983. Anais... Rio de Janeiro: IBC/GERCA, 1983. p.111-113

[5] CARVALHO, V.D., Cafeicultura empresarial: produtividade e qualidade. Lavras: UFLA/FAEPE, 1998. 73 p. (Curso de Especialização Pós-Graduação Latu sensu).

[6] CARVALHO, V.D.; CHAGAS, S.J.R.; CHALFOUN, S.M.; BOTREL, N.JUSTE; JÚNIOR, E.S.G.. Relação entre a composição físico-química e química do grão beneficiado e a qualidade de bebida do café. Pesquisa Agropecuária Brasileira, Brasilia, v; 29, n.3, p. 449-454, mar. 1994.

[7] CLIFFORD, M.N.; WIGHT, J. Chlorogenic acids their complex nature and routine determination in coffee beans. Food Chemistry, Essex v. 4, p. 63-71, 1979.

[8] FRANÇA, A. S.; OLIVEIRA, L.S.; BORGES, M.L.A.; VITORINO, M.D. Evolução da composição do extrato aquoso de café durante o processo de torrefação. Revista Brasileira de Armazenamento, Especial café, n.2, p.3747, 2001.

[9] INSTITUTO ADOLFO LUTZ. Normas analiticas, métodos químicos e físicos para análise de alimentos. 3". ed. São Paulo: Instituto Adolfo Lutz, 1985. v.1.

[10] LOPEZ, F.C. Determinação quantitativa das principais substâncias utilizadas para fraudar o café torrado e moído. Revista do Instituto Adolfo Lutz, v. 43, n. 2, p.3-8, 1983.

[11] PEDRO, N.A.R; BADOLATO, M.I.C.; FREITAS, V.P.S.; CHIARINI, P.F.T. Avaliação da qualidade do café torrado e moído processado na região de Campinas, estado de São Paulo. Revista do Instituto Adolfo Lutz, v.56, n.1: p.113-117, 1996.

[12] PICTET, G.; REHACEK, J. Contróles analytiques du degré de torrefaction. In: COLÓQUIO CIENTÍFICO INTERNACIONAL SOBRE O CAFÉ, 10. 1982, Salvador. Resumos... Salvador: ASIC, 1982. p. 219-234.

\section{6 - AGRADECIMENTOS}

À FAPEMIG-FIEMG pela concessão da bolsa de estudo. 